\title{
Dez anos de jornalismo digital no Jornal de Notícias
}

\author{
Manuel Molinos, Nuno Marques e Paulo Ferreira*
}

\section{Introdução}

Este texto pretende analisar, de forma sucinta, o que foram os primeiros dez anos de jornalismo digital no Jornal de Notícias $(J N)$ e o que se pretende no futuro mais próximo. $\mathrm{O}$ facto de o JN ter sido o primeiro diário português a lançar uma edição online, no dia 27 de Julho de 1995, teve imensas virtudes. Contudo, o projecto sofreu avanços e recuos que estão (ainda) longe de redundar na existência de um site que corresponda à dimensão e à ambição do $J N$. A breve explicitação das razões que nos trouxeram até este ponto está, também, entre os objectivos deste texto. Da mesma forma, tentaremos traduzir as apostas que a actual direcção do jornal tem em mente, para que seja possível responder às exigências de quem nos procura, num meio que, para citar Manuel Castells (2004), se transformou no "tecido das nossas vidas". Usaremos alguns dados, resultantes de estudos feitos internamente, no intuito de caracterizar o "público" que escolhe o site do $J N$ para se actualizar ou para apenas discutir, partilhando-os, os temas que são do seu interesse. As características dos fóruns merecerão, igualmente, uma curta referência. Na linha do que escreve Dan Gillmor, parece-nos que o facto de estarmos perante um meio que permite "dispor de comunicações de muitos para muitos e de alguns para alguns” (Gillmor, 2005) justifica, por si só, uma pequena análise.

\section{0 início}

$\mathrm{O}$ arranque do site do $J N$ teve uma componente muito mais técnica do que editorial. As primeiras discussões sobre a criação do site remontam a 1994, ano em que o facto de nos fóruns internacionais se falar, cada vez com mais insistência, do online não escapou aos mais “curiosos” no JN. A verdade, porém, é que essa curiosidade acicatou mais o espírito da Direcção Técnica do que da Direcção Editorial. Em bom rigor, foi o esforço daquela que fez nascer o site do JN. 
Inicialmente, cabia a alguns jornalistas - os que estavam mais à vontade com as novas tecnologias - a tarefa de "alimentar" a edição online. Ao final do dia, esse grupo de jornalistas recolhia os textos das principais notícias da edição do da seguinte, colocava-as num formato informático compatível e num dos poucos $\mathrm{PC}$ que existiam na redacção enviava os referidos textos, via modem, para a Caleida, a empresa que albergava as páginas do $J N$. Nessa altura, o sistema informático do $J N$ (Linotype) não assentava nas plataformas mais comuns na época, quer PC quer Macintosh. Ao longo da evolução deste processo, o número de secções e de textos transpostos foi sendo alargado, mas estava longe de abarcar toda a edição em papel.

Este processo funcionou durante um período relativamente curto. $\mathrm{O} J \mathrm{~N}$ assumiu, então, que a criação de uma edição electrónica devia ser acelerada. Os objectivos eram: transpor, tanto quanto possível, a edição em papel para o online e criar novas formas de relação com o leitor, explorando as potencialidades abertas por este novo meio.

Para avançar com este processo, a Direcção do $J N$ destacou dois jornalistas (Hélder Bastos e Nuno Marques) e atribuiu a coordenação do processo ao então director-adjunto, Fernando Martins. Continuava a caber à Direcção Técnica a liderança do projecto (aliás, na primeira fase, antes da existência de jornalistas dedicados à tarefa, foi a própria Direcção Técnica que, muitas vezes, sugeriu o tipo de conteúdos que a empresa poderia começar a colocar online).

O JN iniciou, então, uma série de trabalhos de desenvolvimento do projecto de criação de uma verdadeira edição electrónica. É contratada uma empresa possuidora do know-how técnico, quer ao nível da gestão do site e servidor, quer ao nível da criação das páginas (Centro de Computação Gráfica - CCG, ligado à Universidade de Coimbra). O processo de amadurecimento do projecto decorre ao longo de vários meses. A ideia era alcançar um compromisso entre a inovação tecnológica e os recursos abertos por ela e a acessibilidade ao número mais alargado possível de leitores.

Globalmente, o projecto de edição electrónica visava transpor para o formato electrónico o maior número possível de conteúdos da edição em papel; criar uma secção de "Última Hora" que ia sendo actualizada ao longo do dia até ser substituída pela edição final "saída" do papel; criar novas secções (incompatíveis com a edição tradicional), como o "Desabafe connosco", os Fóruns, O "Dicionário de InternetêsPortuguês). Estas novas secções eram consideradas uma das principais mais-valias do projecto electrónico.

Pretendia-se ainda que os dois jornalistas funcionassem como uma mini-redacção autónoma, alimentando a edição electrónica a partir, quer das informações de agência, quer dos trabalhos dos outros jornalistas. Na prática, apenas funcionou a actualização de notícias a partir das agências, em particular da Lusa.

Qualquer uma das secções que integrava o $J N$ electrónico registou uma enorme resposta dos leitores com dados muito curiosos: uma tendência contrária à registada na edição tradicional, em que o número de consultas descia substancialmente ao fim-de-semana e, em particular, ao domingo; uma procura muito intensa por parte dos 
portugueses residentes no estrangeiro com características que eram então algo surpreendentes, já que em grande parte se tratava de emigrantes altamente qualificados ou de estudantes do ensino superior. O número de leitores crescia também a um ritmo muitas vezes surpreendente para as próprias pessoas envolvidas.

Ao longo de alguns anos, a Internet no $J N$ esteve apenas acessível através do computador atribuído aos jornalistas da edição online, fisicamente colocados num espaço próprio dentro da redacção. Foram eles que começaram a instruir grande parte da redacção sobre a utilização desse meio e quais os recursos disponibilizados e actuando, muitas vezes, como intermediários no processo de recolha de informações ou de contactos com fontes. Apesar da aposta do jornal - forte numa fase inicial e menos intensa posteriormente -, os meios técnicos foram sempre bastante limitados.

À distância, é possível identificar a quebra no "vigor" do projecto com a passagem da liderança para a Direcção Editorial. Assim que o processo entra em velocidade de cruzeiro e a vertente técnica está relativamente estabilizada, a gestão passa a caber à Direcção do JN. É nessa fase que o projecto perde a atitude de constante busca de inovação e de implementação de novas soluções.

Em 1999, o processo estava já perfeitamente estagnado.

\section{A (não) resposta à bolha}

De facto, o investimento - logístico e editorial - no site frustrou as expectativas iniciais. Para o bem e para o mal. É que, quando a chamada bolha da Internet estourou, no final da década de 90, o JN não se ressentiu, do ponto de vista empresarial, dessa circunstância. Seja como for, a falta de investimento não parece, a esta distância, compaginável com o que entretanto foi alcançado. Um estudo feito internamente mostrava, já em 1996, as potencialidades do meio. Vejamos alguns factos.

Havia 70 países com consultas regulares; $44 \%$ das consultas eram feitas a partir de Portugal; $56 \%$ do resto dos países, com os EUA a liderar (o que tem seguramente a ver com a realidade dos motores de busca), seguidos do Canadá, Brasil, Reino Unido, Austrália, França, Alemanha e Suíça; num ciclo semanal típico, havia cerca de 135 mil consultas; foram contabilizadas cerca de 4,5 milhões de consultas em 1996; a distribuição por idades mostrava que as faixas 19-24 anos e 25-35 eram predominantes; e os visitantes eram, sobretudo, estudantes universitários e quadros/gestores.

Apesar destes indicadores, o JN continuou apenas a colocar no seu site aquilo que era o grosso da edição impressa. No último redesenho do site, há cerca de três anos, procurou dar-se um maior destaque à área em que o jornal tem uma das suas maiores forças - a informação local e o desporto. Para isso, foram criados pesquisadores por localidade. Ao mesmo tempo, passaram a existir microsites para clubes de futebol.

A equipa que faz o jornalismo digital do $J N$, composta por quatro pessoas, já consegue, hoje, ter produção própria em alguns dossiers. Além disso, a opção passa por fazer o que pode ser considerada uma última hora ligeira, numa base dead-line news. 
Apesar de todos os constrangimentos, os dados mais recentes voltam a acentuar a boa recepção do site. Em Maio de 2005, o online teve o melhor mês, quando comparado com os doze imediatamente anteriores: 2,3 milhões de visitas.

\section{Os fóruns do JN}

Os fóruns do JN online constituem uma mais-valia do site em termos de interactividade e marcam um espaço muito próprio nos domínios “pt”, traduzido, sobretudo, pelo particular perfil do utilizador. Apesar de transparecer o pouco à-vontade com o uso das novas tecnologias de informação e comunicação, é um público fiel. Os seus nick names são já bem conhecidos dos moderadores dos fóruns e animam aqueles espaços quotidianamente. É adulto. É instruído e especialmente atento à actualidade. Uma grande fatia reside além-fronteiras. Muitos dos utilizadores são emigrantes e encontram no JN online o espaço para analisar o país à distância.

Diariamente, o JN online regista a média de uma centena de participações, metade das quais constituem respostas a comentários dos utilizadores, provando que o leitor pretende não só deixar a sua opinião, mas envolver-se em discussões sobre temas que os próprios participantes vão impondo. Esta "liberdade" de discutir assuntos não sugeridos pelos moderadores resulta de uma forma muito interessante. Ao contrário da maioria dos jornais online portugueses, o $J N$ electrónico não propõe temas para debates, nem tão-pouco o suporte utilizado permite comentar artigo a artigo. É verdade que já experimentou a solução, mas o resultado apontou sempre para uma enorme redundância com os fóruns de temas abertos. Não é, portanto, necessário criar mecanismos especiais para acontecimentos de grande relevância, como, por exemplo, a morte de João Paulo II ou o aumento do IVA. O próprio utilizador marca a actualidade. E não se deixa saturar por assuntos tantas vezes "mastigados" nos jornais ou nas televisões. Varia de tema constantemente, mesmo quando há grandes acontecimentos a dominar a actualidade. É, no fundo, um self media interactivo. Serve-se quando as mensagens lhe são receptivas, mas rejeita facilmente conteúdos vazios de interesse.

\section{As apostas e as limitações}

A definição das estratégias a seguir no futuro está, neste momento, limitada por dois factores. Para o bem e para o mal, a ligação empresarial ao portal de Internet Sapo, decorrente do facto de o JN se encontrar no mesmo grupo que detém o portal, obriga a procurar sinergias que, por vezes, limitam as opções editoriais. Por outro lado, o processo, em curso na altura da elaboração deste texto, de venda da empresa em que o JN se insere não permite, pelo menos a curto prazo, grandes decisões.

Apesar disso, a Direcção Editorial do JN tem como objectivo alcançar uma maior interligação entre o papel e o online. O primeiro passo foi dado com a integração dos jornalistas do online no mesmo espaço físico dos restantes, o que permite, desde logo, uma melhor articulação com as Editorias e com as Chefias, factor muitas vezes fun- 
damental para actualizar matérias de última hora, para a mudança de inquéritos de opinião ao leitor ou mesmo para a definição de novos dossiers.

Apostar fortemente num modelo em que a edição electrónica seja uma actualização permanente da edição em papel é outro dos desafios. Quem nos lê de manhã não tem que esperar pelo dia seguinte para conhecer o follow-up daquilo que lhe interessa.

A Direcção Editorial entende que avançar para os conteúdos parcialmente pagos é um processo irreversível. Ainda assim, a última hora manter-se-á gratuita.

Finalmente, está em curso um trabalho em parceria com o departamento de informática da Universidade do Minho, no sentido de monitorizar o site para, a partir daí, se desenharem novas estratégias que possam ir ao encontro dos anseios e desejos de quem procura a edição online do JN.

\section{Referências bibliográficas}

Castells, M. (2004) A Galáxia Internet - Reflexões sobre Internet, Negócios e Sociedade, Lisboa: Fundação Calouste Gulbenkian.

Gillmor, D. (2005) Nós, os Media, Lisboa: Editorial Presença. 